\title{
Randomised controlled trial of effect of terbutaline before elective caesarean section on postnatal respiration and glucose homeostasis
}

\author{
Gabriella Eisler, Ragnhild Hjertberg, Hugo Lagercrantz
}

\begin{abstract}
Aim-To determine if terbutaline given to mothers before elective caesarean section facilitates neonatal respiration and metabolism.

Methods-A randomised controlled trial of 25 full term infants delivered by elective caesarean section was conducted. The mothers received a continuous infusion of terbutaline or saline 120-0 minutes before birth. Umbilical artery blood was collected at birth and analysed for blood gases and catecholamines. The lung function of each infant was assessed two hours after birth, and blood pressure, heart rate, blood glucose and body temperature were monitored until 24 hours of age.

Results-The infants of the treated mothers $(n=13)$ had significantly higher $d y-$ namic lung compliance $(p<0.001)$, lower airway resistance $(p<0.001)$, and respiratory frequency than control infants $(n=12)$. Blood glucose and adrenaline concentrations were significantly higher in the treated group $(p=0.0014$ and $p<0.01)$. None of these infants had any clinical respiratory difficulties; there were two cases of transient tachypnoea in the control group. No negative side effects due to the terbutaline treatment were seen among the infants. The mothers felt no discomfort caused by the terbutaline infusion, although they bled more during surgery $(\mathrm{p}=\mathbf{0 . 0 3})$.

Conclusion-Stimulation of the $\beta$ adrenoceptors in utero with terbutaline infusion to the mothers promotes neonatal respiratory and metabolic adaptation after elective caesarean section.
\end{abstract}

(Arch Dis Child Fetal Neonatal Ed 1999;80:F88-F92)

Keywords: caesarean section; terbutaline; lung function; blood glucose

Newborn infants delivered by elective caesarean section before the onset of labour have a higher respiratory morbidity. ${ }^{1-8}$ The incidence of respiratory distress syndrome (RDS) at term was 2.2 per 1000 deliveries, and of transient tachypnoea of the newborn (TTN), 5.7 per 1000 deliveries, according to a recent UK study. ${ }^{9}$ Infants delivered by elective caesarean section had an odds ratio of 6.8 of developing respiratory problems compared with vaginally delivered infants and 2.9 compared with infants delivered by caesarean section during labour. $^{9}$
The explanation for the association between elective caesarean section and respiratory problems could be that labour is important for neonatal adaptation. The squeezing and squashing of the infant during vaginal delivery triggers a surge of hormones at birth, particularly catecholamines. ${ }^{10-16}$ These catecholamines, particularly adrenaline, inhibit lung liquid secretion and stimulate its absorption, which enhances aereation of the lungs. ${ }^{1}{ }^{817}$

Studies of transepithelial electrical potential difference and ion transport, which show dysfunction in infants delivered by elective caesarean section and in infants with TTN, support an important role for labour in the transition of pulmonary ion transport at birth. ${ }^{18}$

Several animal and human studies have shown that increased catecholamine concentrations during labour also promote surfactant secretion, which is essential for the final adaptation of the lung to air breathing. ${ }^{8}{ }^{19}$ Antepartum administration of $\beta$ stimulating drugs to premature infants has reduced the incidence of RDS. $^{20}{ }^{21}$ Studies of fetal rabbit lung have shown increased lung volumes, reduced fluid in the airways, and a more rapid dehydration of the lungs postnatally in fetuses treated with a $\beta_{2}$ stimulating drug (terbutaline). Several tentative mechanisms behind this $\beta$ mimetic mediated response have been suggested, such as dilatation of the bronchioles and a direct effect on the production of pulmonary fluid by the respiratory epithelium. ${ }^{22}$

An association between catecholamines and metabolic adaptation has been shown. Term infants delivered by caesarean section before labour have lower cord blood glucose than vaginally delivered infants. ${ }^{13}$ There is a higher incidence of hypoglycaemia in term neonates born by caesarean section than by vaginal delivery. ${ }^{13} 2324$

Our hypothesis is that the effects of labour could be simulated by a $\beta$ mimetic preoperatively administered to the mother. This hypothesis is corroborated by the finding that $\beta$ adrenoceptor blocking drugs impair neonatal respiratory adaptation ${ }^{25-28}$ and are associated with neonatal hypoglycaemia. ${ }^{27-29}$ To test this hypothesis, we performed a randomised controlled study by treating women before elective caesarean section with a $\beta$ adrenoceptor agonist (terbutaline), and we analysed the neonatal adaptation of the offsprings with respect to lung function, glucose homeostasis, and body temperature. Terbutaline was chosen as it is often routinely used to inhibit preterm labour when caesarean section is planned. 
Table 1 Infant data [Mean (1 SD)]

\begin{tabular}{lll}
\hline & Terbutaline $n=13$ & Controls $n=12$ \\
\hline $\begin{array}{l}\text { Gestational age } \\
\quad(\text { weeks) }\end{array}$ & $38.9(0.9)$ & $38.7(0.7)$ \\
Birthweight $(\mathrm{g})$ & $3310(425)$ & $3338(553)$ \\
Birth height $(\mathrm{cm})$ & $49(2)$ & $48(3)$ \\
Apgar score $1 \mathrm{~min}$ & $9.0(0)$ & $8.8(0.4)$ \\
Apgar score 5 min & $9.9(0.3)$ & $9.8(0.4)$ \\
Cord blood BE & $-5.2(3.2)$ & $-2.7(2.2) \mathrm{p}<0.01$ \\
Cord blood pH & $7.28(0.05)$ & $7.30(0.03)$ \\
\hline
\end{tabular}

\section{Methods}

Twenty five full term infants, all healthy and delivered by elective caesarean section using spinal anaesthesia, were included in the study. The indication for section was breech presentation or cephalopelvic disproportion, previous caesarean section, or humanitarian reasons. All mothers were healthy, median age 31 (23-43) years, with normal pregnancies and normal blood pressure and blood glucose ( $\beta$ glucose) during pregnancy. Four of the mothers were smokers, two in each group. Data regarding the infants are shown in table 1.

The mothers were randomised according to a double blind protocol to receive either $\beta$ mimetics or placebo. Maternal blood pressure, heart rate, and $\beta$ glucose were measured two hours preoperatively, thereafter an infusion was initiated with terbutaline: $0.30(0.30-0.45)$ $\mathrm{mg} / \mathrm{h}$ (median and range). The controls were given saline using the same volume. Total dose of terbutaline was $0.80(0.45-1.00) \mathrm{mg}$. The infusion was given until birth. Heart rate, blood pressure, and $\beta$ glucose were monitored during infusion to detect possible side effects.

Arterial blood was sampled from the double clamped umbilical cord at delivery for calcium agonist analysis (adrenaline, noradrenaline, and dopamine) and for blood gases $\left(\mathrm{Po}_{2}, \mathrm{Pco}_{2}\right.$, $\mathrm{pH}$, base excess).

The newborn infants were transferred in a transport incubator from theatre to the maternity ward where they were dressed and kept in open cots at normal room temperature. Body temperature, respiratory frequency, blood pressure, heart rate, and $\beta$ glucose were monitored at 30 minutes and at one, two, six and 12 hours after birth. The infants were weighed daily until discharged.

Two hours after birth lung function was tested. Tidal volume, dynamic lung compliance, and airway resistance were measured three times consecutively during quiet spontaneous sleep using a Bicore CP-100 pneumotachometer. A soft rubber mask was held tightly over the baby's mouth and nose so that no air could leak out. When the baby was breathing quietly the measurements were made with a passive mechanics occlusion technique. ${ }^{30}$ One doctor performed all measurements on all infants without knowledge of the mode of treatment. Complications such as respiratory problems, feeding difficulties, or other complications that occurred during the hospital stay were recorded.

The neonatal and maternal $\beta$ glucose samples were taken from the infants by heel-prick and from the mothers' fingertips and analysed on an Accu-Chek II monitor (Boehringer Mannheim Corporation, Germany). The blood gases were analysed immediately on a Radiometer ABL 500. The samples for calcium agonists were collected in chilled plastic tubes containing EDTA-glutathion, kept on ice, and centrifuged within 15 minutes. The plasma was separated, immediately frozen, and saved for later analysis with high performance liquid chromatography (HPLC).

The Mann-Whitney $U$ test for unpaired measurements and the Wilcoxon rank sum test for paired measurements were used for statistical evaluation. A value of $\mathrm{p}<0.05$ was regarded as significant.

The project was approved by the ethical committee at the Karolinska Hospital. Informed consent was obtained from both parents.

\section{Results}

None of the women felt any discomfort from the terbutaline infusion, apart from a few cases of slight palpitation. However, actual maternal
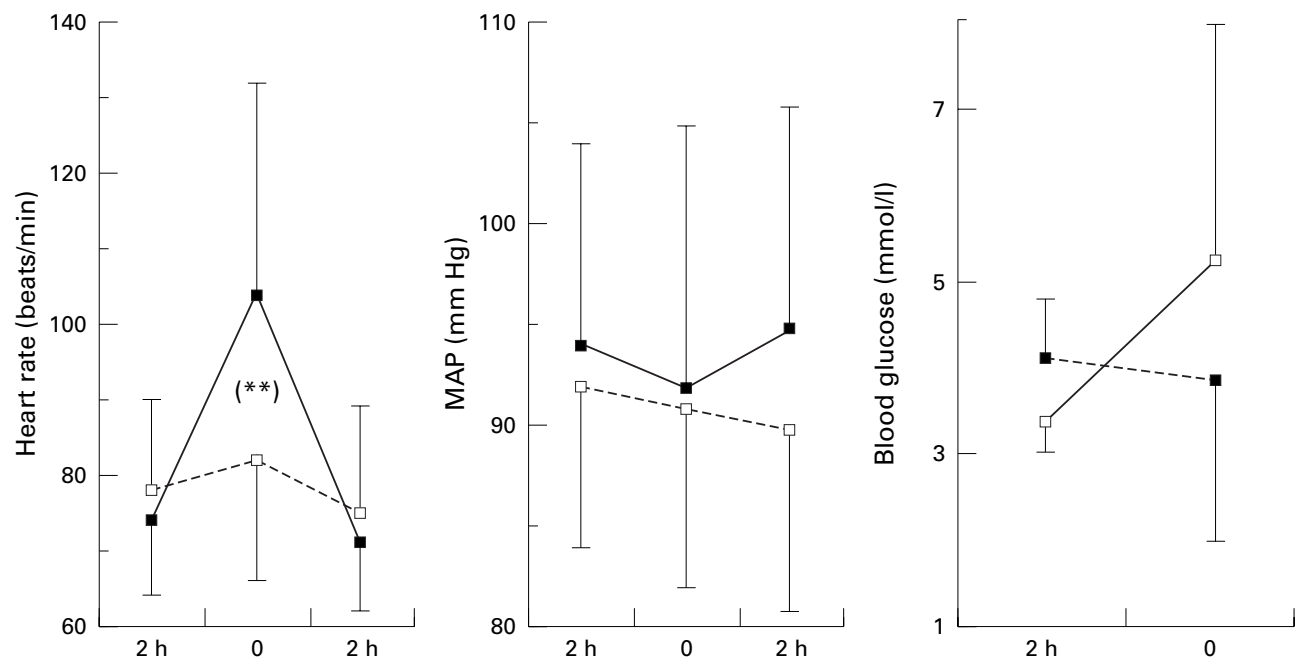

Figure 1 Maternal heart rate, mean arterial blood pressure (MAP), and blood glucose concentrations 2 hours

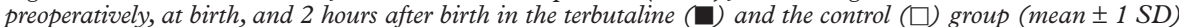
$(* * p<0.01)$. 

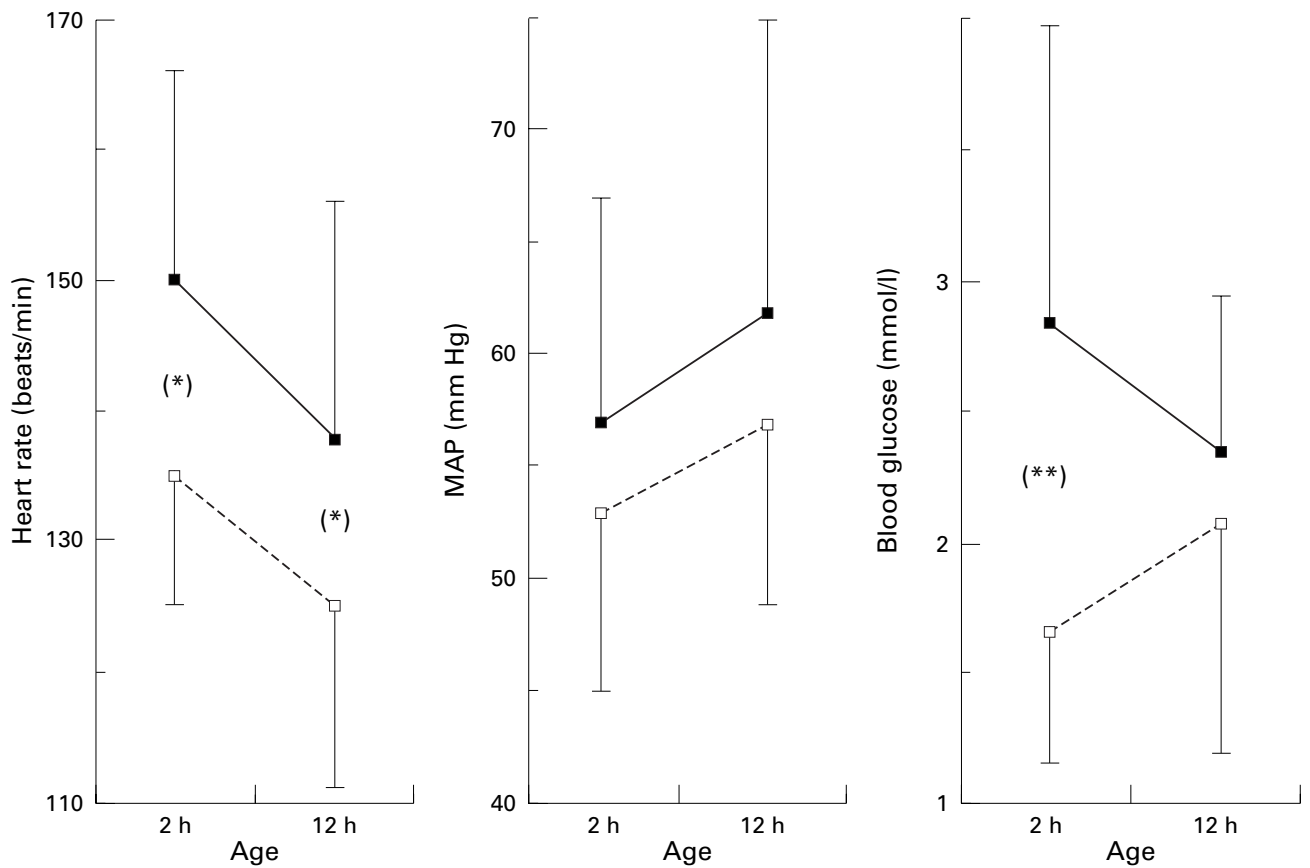

Figure 2 Neonatal heart rate, mean arterial blood pressure (MAP), and blood glucose concentrations in the terbutaline () and control ( $\square$ ) groups (mean $\pm 1 S D)\left({ }^{\star} p<0.05,{ }^{\star *} p<0.01\right)$.

heart rate was significantly higher in the terbutaline group than in the controls after two hours of infusion $(\mathrm{p}<0.01)$ (fig 1$)$. Before infusion the heart rate and blood pressure were normal and did not differ between the groups. Blood pressure did not increase in either group after infusion (fig 1).

Before infusion, blood glucose was normal in the control group and a little low in the terbutaline group two hours before surgery. The mothers had by then been fasting for over 6 hours. Just before birth $\beta$ glucose had increased significantly in the terbutaline group $(\mathrm{p}<0.01)$ whereas in the control group $\beta$ glucose was slightly decreased (fig 1).

The amount of peroperative bleeding was significantly higher in the terbutaline group than in the control group: $600 \mathrm{ml}(300-2100)$ and $325 \mathrm{ml}$ (200-800), respectively (median and range $)(\mathrm{p}<0.05)$. This bleeding could be stopped by administering $1 \mathrm{mg}$ intravenous propranolol (a non-selective $\beta$ adrenoceptor blocker) after the baby was born. Six out of 13 terbutaline treated mothers received propranolol. In all six cases the bleeding decreased after the injection. Where bleeding was excessive $(2100 \mathrm{ml})$, neither additional oxytocin nor propranolol was administered, and the bleeding persisted postoperatively.

In the control group two cases had a reported atonic uterus. Both contracted adequately after additional administration of oxytocin $(5 \mathrm{ml}$ bolus dose $+50 \mathrm{ml}$ in continuous infusion). Two patients in the control group received propranolol.

Thirteen infants received terbutaline and 12 infants received saline and served as controls. The heart rate was significantly higher among the infants in the terbutaline group than in the control group at two hours $(\mathrm{p}<0.05)$ and at 12 hours $(p<0.05)$ after birth. A decline over time was seen in both groups. The blood pressure was normal and similar in the two groups at two and at 12 hours (fig 2). One infant in the terbutaline group had a hip joint dislocation, one had hyperbilirubinaemia (not treated), and two infants lost more than $10 \%$ of their body weight. Two infants in the control group had transient tachypnoea, one had a severe hypoglycaemia ( $\beta$ glucose $0.8 \mathrm{mmol} / \mathrm{l}$ ) which required glucose infusion, and one infant lost more than $10 \%$ in body weight.

Arterial blood gases did not differ between the groups, except for the base excess which was significantly higher in the terbutaline treated group $(\mathrm{p}<0.001)$. Apgar score and birthweight were equal in both groups (table 1). The mean axillary temperature tended to be higher in the terbutaline treated group, although this was not significant (fig 3).

The infants of the mothers who had received $\beta$ agonists had significantly lower airway resistance $(\mathrm{p}<0.001)$ and higher lung compliance $(p<0.001)$ than controls. Adrenaline concentrations correlated significantly with dynamic lung compliance in the terbutaline treated neonates $(r=0.74) \quad(p<0.01)$, but no such correlation was found in the controls.

The respiratory frequency was lower in the terbutaline treated group (table 2). The difference was significant at 30 minutes $(p<0.01)$, at one hour, and 12 hours $(\mathrm{p}<0.05)$, but not at two and six hours (fig 3 ). There was a positive correlation between airway resistance and respiratory frequency at one and two hours in the terbutaline group $(\mathrm{r}=0.76)(\mathrm{p}=0.005)$, but not in the control group.

The adrenaline concentrations were significantly higher in the terbutaline group than in the control group: $4.4(1.0-5.6) \mathrm{nmol} / 1$ vs $1.7(0.3-3.8) \mathrm{nmol} / 1$ (median and range) $(p<0.01)$. The noradrenaline concentrations showed no significant difference, but were 

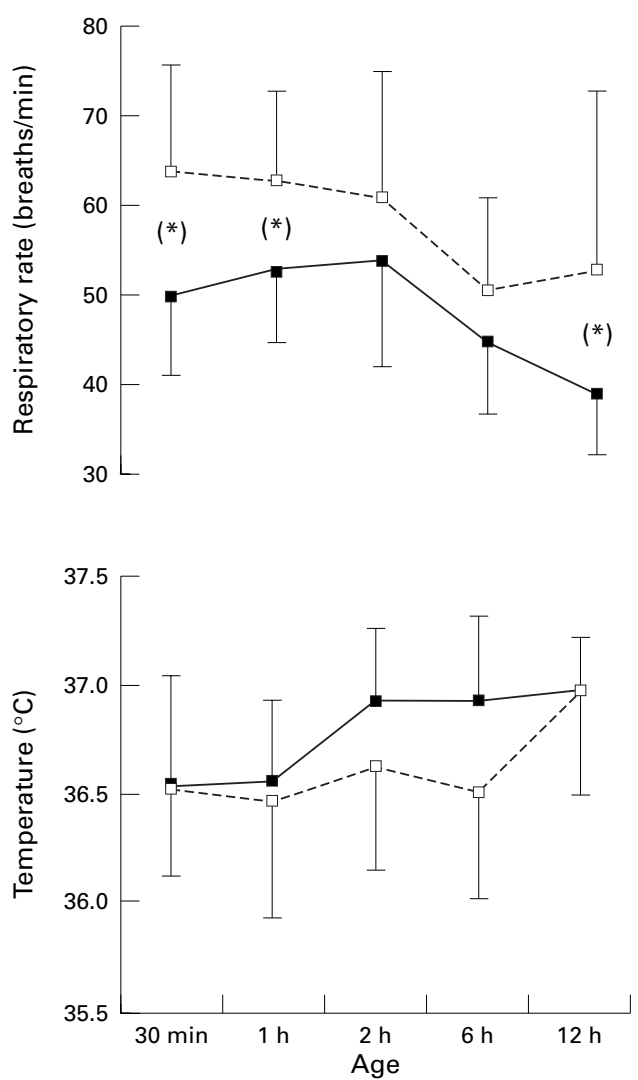

Figure 3 Respiratory rate and axillary temperature in the

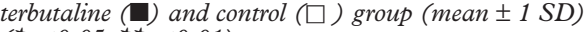
$\left({ }^{\star} p<0.05,{ }^{\star *} p<0.01\right)$.

Table 2 Dynamic lung compliance, airway resistance and respiratory rate at 2 hrs of age [Mean (1 SD)]

\begin{tabular}{lll}
\hline & Terbutaline $n=13$ & Controls $n=12$ \\
\hline $\begin{array}{l}\text { Compliance }(\mathrm{ml} / \mathrm{cm} \\
\left.\mathrm{H}_{2} \mathrm{O}\right)\end{array}$ & $3.4(1.4)$ & $2.1(0.8)(\mathrm{p}<0.001)$ \\
$\begin{array}{c}\text { Resistance }(\mathrm{cm} \\
\left.\mathrm{H}_{2} \mathrm{O} / \mathrm{l} / \mathrm{s}\right)\end{array}$ & $21(4)$ & $37(4)(\mathrm{p}<0.001)$ \\
$\begin{array}{c}\text { Respiratory rate } \\
\text { (breaths/min) }\end{array}$ & $54(12)$ & $61(14)(\mathrm{NS})$ \\
\hline
\end{tabular}

higher in the terbutaline group: 16.2 (3.2-38.0) $\mathrm{nmol} / \mathrm{l}$ ws 10.4 (3.0-27.7) nmol/1.

The infants in the control group developed hypoglycaemia (defined as blood glucose $<2.0$ $\mathrm{mmol} / \mathrm{l}$ ) more often than the terbutaline treated infants. Two hours after birth the mean blood glucose value was significantly higher in the terbutaline group than in the control group $(p<0.01)$. Hypoglycaemia-with or without symptoms - was seen in nine out of 12 infants $(75 \%)$ in the control group two hours after birth. After 12 hours eight of the infants $(67 \%)$ still had a blood glucose concentration below $2.0 \mathrm{mmol} / \mathrm{l}$ despite the fact that they had all been fed after the observation of the first low value. In the terbutaline group only one out of $13(8 \%)$ was hypoglycaemic at two hours, and three out of $13(23 \%)$ at 12 hours of age (fig 2 ).

\section{Discussion}

Our main finding was that infants delivered by elective caesarean section whose mothers were given terbutaline had lower respiratory morbidity and better lung function. They also had higher adrenaline and blood glucose concen- trations than the infants in the control group. This finding supports our hypothesis that stimulation of $\beta$ adrenoceptors during normal birth is possible to attain by treating the mothers with a $\beta$ adrenoceptor agonist before elective caesarean section.

The lower respiratory morbidity and higher dynamic lung compliance in the terbutaline treated group suggest that the lung liquid was more effectively removed ${ }^{3} 1722$ and/or more surfactant released. ${ }^{819}$ This finding corroborates our earlier observation of a correlation between dynamic lung compliance and catecholamine surge at birth.

The treatment also increased $\beta$ glucose concentrations. The mean $\beta$ glucose value in the terbutaline group was significantly higher than in the control group and in the same range as that previously reported for normal vaginally delivered infants. ${ }^{313}$ The incidence of asymptomatic hypoglycaemia in the control group was higher than reported before, ${ }^{20}{ }^{21}$ possibly at least partially due to the selected material; all infants were term and appropriate for gestational age - that is, explicitly "unstressed."

Body temperature tended to be higher in the terbutaline group than in the control group. An earlier study has shown that infants delivered vaginally and sustaining labour have higher body temperatures than infants delivered by elective caesaerean section. ${ }^{30}$

Terbutaline has a direct stimulating effect on the $\beta$ adrenergic receptors. The effect of terbutaline could also be mediated indirectly by stimulation of adrenaline release. ${ }^{17}$ The first mechanism is well known and can be further supported by the fact that all terbutaline treated infants had better lung function and higher $\beta$ glucose concentrations than the control infants although the catecholamine concentrations were not always higher. Higher catecholamine concentrations and correlation between adrenaline concentrations and lung compliance in the terbutaline group indicate that an increased secretion of endogenous adrenaline might have mediated the terbutaline effect.

No major side effect of the terbutaline treatment was observed in the mothers except for increased obstetric bleeding. Propranolol administered in six cases limited the bleeding. An immediate postpartum injection of propranolol to all the women who received terbutaline might have prevented the increased bleeds, at least partially.

The terbutaline dose used in our study was sufficient to result in significant differences in dynamic lung compliance, airway resistance, and $\beta$ glucose concentrations between the infants of the treated and the non-treated women. It could possibly be lowered to avoid increased maternal bleeding. Alternative ways of administering the drug could also be discussed, such as postnatal inhalation.

Whether preterm infants ( $<37$ weeks) should be given terbutaline before elective caesarean section must be investigated in a separate study, as their $\beta$ adrenergic receptors are not sufficiently mature. ${ }^{17} 2231$ In a recent British survey normal full term infants deliv- 
ered by elective caesarean section developed impaired neonatal respiration adaptation to varying degrees, particularly when the caesarean section was performed before the 39th gestational week. ${ }^{9}$

We conclude that postnatal adaptation after elective caesarean section can be promoted by preoperative administration of $\beta$ adrenergic drugs to the mother. This may not be of clinical importance for all infants born by elective caesarean section. However it could be relevant for infants born between 37 and 39 weeks $^{21} 2231$ or large for date infants, ${ }^{32}$ if the maternal side effects such as bleeding can be limited.

This study was supported by the Swedish Medical Research Council (Grant No 5234).

1 Faxelius G, Hägnevik K, Lagercrantz H, Lundell B, Irestedt $\mathrm{L}$ Catecholamine surge and lung function after delivery. Arch Dis Child 1983;58:262-6.

2 Hägnevik K, Lagercrantz H, Sjöqvist B-A. Establishment of functional residual capacity in infants delivered vaginally functional residual capacity in infants delivered vaginally and by elective

3 Irestedt L, Lagercrantz H, Belfrage P. Causes and consequences of maternal and fetal sympathoadrenal activation during parturition. Acta Obstet Gynecol Scand Suppl 1984;118:111-5

4 Milner AD, Saunders RA, Hopkin IE. Effects of delivery by caesarean section on lung mechanics and lung volume in the human neonate. Arch Dis Child 1978;53:545-8.

5 Patel DM, Donovan EF, Keenan WJ. Transient respiratory difficulty following cesarean delivery. Biol Neonate 1983;43:146-51

6 Greenough A, Lagercrantz H. Catecholamine abnormalities in transient tachypnoea of the premature newborn. F Perinat Med 1992;20:223-6.

7 Usher RH, Allen AC, Mc Lean FH. Risk of respiratory distress syndrome related to gestational age, route of delivery tress syndrome related to gestational age, route of delivery 32 .

8 Olver RE. Of labour and the lungs. Arch Dis Child 1981;56:559.

9 Morrison JJ, Rennie JM, Milton PJ. Neonatal respiratory morbidity and mode of delivery at term: influence of timing of elective caesarean section. Br $\mathcal{F}$ Obstet Gynaecol 1995;102:101-6

10 Lagercrantz H, Bistoletti P. Catecholamine release in the newborn infant at birth. Pediatr Res 1977;11:889.

11 Bistoletti P, Nylund L, Lagercrantz H, Hjemdahl P, Ström H. Fetal scalp catecholamines during labor. Am f Obstet Gynecol 1983;147:785-8.

12 Irestedt L, Lagercrantz $\mathrm{H}$, et al. Fetal and maternal plasma catecholamine levels at elective cesarean section under general or epidural anesthesia versus vaginal delivery. $A m f$ Obstet Gynecol 1982;142:1004-10.

13 Hägnevik K , Faxelius G, et al. Catecholamine surge and metabolic adaptation in the newborn after vaginal delivery and caesarean section. Acta Pediatr Scand 1984;73:602-9.
14 Faxelius G, Lagercrantz H, Yao A. Sympatoadrenal activity and peripheral blood flow after birth. Comparison in infants delivered vaginally and by elective cesarean section. F Pediatrics 1984;105:144-8.

15 Jones CM, Greiss FC. The effect of labor on maternal and fetal circulating catecholamines. Am f Obstet Gynecol 1982;144:149-53.

16 Padbury JF, Roberman B, et al. Fetal catecholamine release in response to labor and delivery. Obstet Gynecol 1982;60:607.

17 Walters DV, Olver RE. The role of catecholamines in lung liquid absorption at birth. Pediatr Res 1978;12:239.

18 Gowen CW, Lawson EE, Gingras J, et al. Electrical potential difference and ion transport across nasal epithelium of term neonates: Correlation with mode of delivery, transient tachypnea of the newborn, and respiratory rate. $\mathscr{f}$ Pediatr 1988;113:121-7.

19 Lawson EE, Brown ER, Torday JS, Madansky DL, Tauesch HW, Jr. The effect of epinephrine on tracheal fluid flow and surfactant efflux in fetal sheep. Am Rev Respir Dis 1978; 118:1023-6.

20 Boog G, Ben Brahim M, Gandar R. Beta-mimetic drugs and possible prevention of respiratory distress syndrome. $\mathrm{Br} \mathcal{F}$ Obstet Gynaecol 1975;82:285-8.

21 Bergman B, Hedner T. Antepartum administration of terbutaline and the incidence of hyaline membrane disease in preterm infants. Acta Obstet Gynecol Scand 1978;57:217-21.

22 Bergman B, Hedner T, Lundborg P. Pressure-volume relationship and fluid content in fetal rabbit lung after beta-receptor-stimulating drugs. Pediatr Res 1980;14:1067-70.

23 Srinivasan G, Pildes R, Carramanchi G, et al. Plasma glucose values in normal neonates: a new look. 7 Pediatr 1986;109:114-7.

24 Cole MD, Peevy K. Hypoglycemia in normal neonates appropriate for gestational age. $\mathcal{F}$ Perinatol 1994;XIV:11820.

25 Boutroy MJ. Fetal and neonatal effects of the betaadrenoceptor blocking agents. Dev Pharmacol Ther 1987;10:224.

26 Reed RL, Cheney RB, et al. Propranolol therapy throughout pregnancy: A case report. Anesth Analg 1974;53:214.

27 Gladstone GR, Hordorf A, Gersony WM. Propranolol administration during pregnancy: Effects on the fetus. $f$ Pediatr 1975;86:962.

28 Cottrill CM, Mcallister RG, Gettes L, Noonan JA. Propranolol therapy during pregnancy, labor and delivery: Propranolol therapy during pregnancy, labor and delivery: Evidence for transplacental drug transfer and imp
neonatal drug disposition. $\mathcal{F}$ Pediatr 1977;91:812-14.

29 McBride JT, McBride MC, et al. Hypoglycemia associated with propranolol. Pediatrics 1973;51:1085-7.

30 Christensson K, Siles C, Cabrera T, et al. Lower body temperatures in infants delivered by caesarean section than in vaginally delivered newborn infants. Acta Paediatr Scand 1993;82:128-31.

31 Brown MJ, Olver RE, Ramsden CA, Strang LB, Walters DV. Effects of adrenaline and of spontaneous labour on the secretion and absorption of lung liquid in the fetal lamb. $f$ Physiol 1983;344:137-52.

32 Robert MF, Neff RK, Hubbell JP, Taeusch HW, Avery ME. Association between maternal diabetes and respiratory distress syndrome in the newborn. $N$ Engl $\mathcal{F}$ Med 1976;294:357. 